\title{
¿Voto nacionalista? Las bases electorales de AGE y En Marea en las elecciones autonómicas de 2012 y 2016
}

\author{
¿Nationalist voting? Electoral basis of AGE and En Marea \\ in 2012 and 2016 regional elections
}

José Rama Caamaño · jose.rama@uam.es

UNIVERSIDAD AUTÓNOMA DE MADRID

Carlos Fernández Esquer · carlos.fernandeze@uam.es

UNIVERSIDAD AUTÓNOMA DE MADRID

José Manuel Pantín Morado Correo • jpantin@ucm.es

INSTITUTO ORTEGA Y GASSET

Recibido: 05/12/2017

Aceptado: 16/01/2018

\section{Resumen}

En las diez elecciones que se han celebrado a nivel autonómico en Galicia (de 1981 a 2016) los partidos nacionalistas han obtenido representación política. La evolución del voto a estos partidos ha atravesado tres etapas. En la primera, fueron varias las formaciones que entraron en el Parlamento gallego y lo hicieron con un discurso centrado en el eje territorial y en la defensa identitaria. En la segunda etapa, el Bloque Nacionalista Gallego pasó a ser el partido hegemónico del nacionalismo gallego. Por último, las elecciones de 2012, que constituyen el inicio de la tercera etapa, habrían de marcar un nuevo rumbo electoral: la aparición de Alternativa Galega de Esquerdas y, posteriormente, de En Marea, han alterado la competición política en Galicia en torno a la dimensión nacionalista. Ambas coaliciones, con un discurso claramente galleguista, gozaron del apoyo de un notable número de votantes que, sin embargo, optaron por dichas formaciones no precisamente por su defensa territorial. Este trabajo explora la evolución del nacionalismo gallego, centrándose de manera especial en su tercera fase. Así, buscamos determinar cuáles fueron los principales factores explicativos del voto a Alternativa Galega de Esquerdas en 2012 y a En Marea en 2016.

Palabras clave: AGE, En Marea, Voto Nacionalista, Elecciones Autonómicas, Galicia

\section{Abstract}

In all of the (from 1981 to 2016) elections that took place in Galicia at the autonomous communitie level, the regional parties have obtained electoral representation. The evolution in the vote share for these parties could be divided in three periods. In the first one, various regionalist parties entered in the Galician Parliament employing a discourse focused on the territorial cleavage and on the regional identity. In the second period, the Galician Nationalist Block (Bloque Nacionalista Gallego) was the most relevant regionalist party. Finally, the elections that took place in 2012 — the beginning of the third period-could be considerate as the beginning of a new electoral competition: The emergence of a new party, Leftist Galician Alternative (Alternativa Galega de Esquerdas) and, in the following elections, the emergence of En Marea, had altered the Galician political competition. Both parties, with a regionalist discourse, have obtained an important number of votes, but perhaps not from regionalist voters. The aim of this work is describe the evolution of the galician regionalism, paying special attention to the third period. Thus, we are looking for the main explicative factors of vote for Alternativa Galega de Esquedas in the 2012 elections and for En Marea in 2016.

Keywords: AGE, En Marea, Regionalist Vote, Regional Elections, Galicia. 


\section{INTRODUCCIÓN}

En la actualidad España es uno de los países más descentralizados de Europa (Hooghe et al., 2016). Las comunidades autónomas, que reproducen el esquema parlamentario propio de las instituciones estatales, gozan de una amplia capacidad de gasto público, teniendo más del 50 por ciento de la autonomía fiscal. Además, Galicia, al igual que el resto de comunidades autónomas históricas (País Vasco y Cataluña, pero también Navarra o Andalucía), alcanzó desde un inicio un importante nivel competencial, al acceder a la autonomía política por la vía rápida (artículo 151) que prevé la Constitución Española (CE) de 1978.

De esta forma, el modelo territorial establecido por la CE propició la creación de nuevas arenas autonómicas, en las que, en algunas de ellas, se desarrolló una competición política en torno al eje centro-periferia: la asunción de importantes competencias por parte de las comunidades autónomas hizo que se crearan instancias de poder político regional que favorecieron la aparición de partidos de ámbito sub-estatal (Ocaña y Oñate, 2000).

Desde las primeras elecciones al Parlamento de Galicia celebradas en 1981 y hasta los últimos comicios de 2016, al menos una formación nacionalista ha obtenido representación parlamentaria. Si en los primeros años fueron varios los partidos de ámbito no estatal que accedieron a la Cámara gallega, a partir de las elecciones de 1993 el Bloque Nacionalista Gallego (BNG) sería la única formación de carácter nacionalista. No obstante, en las elecciones de 2012 y 2016 dos nuevos partidos —en las primeras, Alternativa Galega de Esquerdas (AGE), coalición formada por Irmandade Nacionalista-Anova y Esquerda Unida (EU); y en las segundas, En Marea, una coalición electoral integrada por Podemos, Anova y EU- conseguirían un importante número de escaños en el Parlamento de Galicia, haciendo uso de un discurso con marcado acento territorial.

Este trabajo se cuestiona hasta qué punto pueden ser consideradas estas últimas formaciones como partidos nacionalistas strictu sensu1. Para ello, se estudia el perfil de sus votantes, prestando especial atención a las cuestiones relativas al sentimiento de identidad nacional y a las preferencias respecto a la forma de organización territorial del Estado. A partir de las encuestas postelectorales autonómicas del Centro de Investigaciones Sociológicas (CIS), recurrimos a modelos de regresión logística, con el objetivo de identificar las variables que ayudan a explicar la probabilidad de voto a AGE y En Marea, en contraposición al resto de formaciones.

Nuestros análisis sugieren que variables como la identidad nacional o la preferencia por una forma de organización territorial concreta, desempeñan un papel relevante a la hora

\footnotetext{
1 Entendemos como voto nacionalista aquel que se produce a partidos de ámbito no estatal que se caracterizan por hacer de su principal seña de identidad el nacionalismo periférico (Fraile y Pérez-Nievas, 2000). Por lo tanto, un partido nacionalista en sentido estricto es aquel que como eje principal de su discurso tiene la reivindicación de demandas nacionalistas y/o que se autocalifican como nacionalistas (Balcells i Ventura 2007, 64). Sirvan como ejemplo las reivindicaciones consistentes en el disfrute de un mayor autogobierno o en la búsqueda de la independencia de la región respecto al Estado en el que se integra.
} 
de explicar el voto a AGE, pero no resultan estadísticamente significativas para en En Marea. Estos hallazgos pondrían cuestionar la clasificación de En Marea como formación nacionalista, dado que su base electoral está conformada por un cuerpo de votantes que comparte características con Podemos, una formación de ámbito nacional.

El trabajo se estructura en cinco apartados. Tras esta breve introducción, se hace una revisión de la literatura centrada en las dinámicas de competición electoral en Estados compuestos, en el voto nacionalista en la Comunidad Autónoma de Galicia y en la irrupción de AGE y En Marea en las últimas elecciones. A continuación, se presentan los datos y los métodos. Después, se muestran los resultados del trabajo. Por último, se exponen las conclusiones a la luz de los hallazgos encontrados.

\section{REVISIÓN DE LA LITERATURA}

Si algo ha quedado claro tras la celebración de diez elecciones al Parlamento de Galicia es que la competición electoral no ha girado en torno a una única dimensión dominante², sino que ha pivotado principalmente sobre dos ejes: el eje izquierda-derecha ${ }^{3} \mathrm{y}$ el centroperiferia ${ }^{4}$. Esta competición electoral, al menos bidimensional, ha sido a su vez predominante en otras comunidades autónomas españolas y, en general, es extensible a la mayoría de países con sistemas de partidos multipartidistas (Kriesi et al., 2006; 2012).

De esta forma, en el sistema de partidos gallego, formaciones de carácter nacionalista con un discurso que reivindica mayor autonomía o un estado independiente han establecido como dimensión primaria de competición el eje centro-periferia (Alonso, 2012). Este ha sido el caso del BNG, que en las últimas décadas ha monopolizado el discurso nacionalista en la política gallega. Sin embargo, en las recientes elecciones autonómicas de 2012 y 2016, dos partidos, AGE primero y más tarde En Marea, se han presentado como formaciones abiertas a competir en torno a los dos ejes: izquierda-derecha y centro-periferia. Así, y pese a que las nuevas formaciones acostumbran a emerger como partidos nicho (Meguid, 2005; Adams et al., 2006), centrándose principalmente en una sola dimensión de competición ya que surgen como respuesta a las nuevas necesidades políticas que demanda la sociedad (Harmel y Robertson, 1985), en el caso de los nuevos partidos gallegos, más allá de

\footnotetext{
${ }^{2}$ Una dimensión existe cuando se hacen patentes al menos dos posiciones contrarias sobre uno o varios temas. Así, sería posible ordenar las preferencias de los individuos en torno a estos temas Alonso (2012) y Alonso, Gómez y Cabeza (2013).

${ }^{3}$ La dimensión izquierda-derecha hace referencia, principalmente, a las posiciones opuestas en torno al papel que debe desempeñar el Estado en la economía y en la sociedad (si debe intervenir o no, cuánto debe intervenir y, en caso de intervenir, cómo debe hacerlo). Además, hace referencia a otro tipo de cuestiones que guardan una mayor relación con elementos culturales, derechos o valores Alonso (2012) y Alonso, Gómez y Cabeza (2013).

${ }^{4}$ El eje centro-periferia alude a la posición de los partidos respecto al modelo territorial del Estado, así como a la defensa de la identidad nacional del grupo cultural mayoritario respecto a la identidad periférica o viceversa. Para un mayor conocimiento de esta dimensión ver, entre otros, los trabajos de Alonso (2012) y Alonso et al. (2013).
} 
competir solo en lo ideológico — centrándose en temas como la regeneración democrática y la lucha contra la corrupción-, gran parte de su discurso ha girado también en torno al eje nacionalista ${ }^{5}$.

La emergencia de ambas formaciones en el nivel subnacional español se enmarca dentro de las consecuencias que ha tenido la Gran Recesión de 2008 en los sistemas de partidos europeos. De forma notable, en los últimos años han surgido nuevos partidos o incrementando su porcentaje de votos formaciones que otrora ocupaban una posición menos relevante en sus respectivos países (Casal Bértoa y Rama, 2017). La crisis económica ha acelerado los procesos de desalineamiento y realineamiento electoral (Hutter, Kriesi y Vidal, 2018) y, como consecuencia de ello, los partidos populistas de izquierda y derecha, así como las formaciones anti-establishment —en su mayoría nuevos partidos-, han resultado los más beneficiados (Hernández y Kriesi, 2016: 203). Sin embargo, lo relevante del caso español es que el nivel subnacional se ha anticipado al nivel nacional en este proceso de «cambio" en el sistema de partidos, circunstancia que subraya su importancia y hace pertinente su estudio (Scantamburlo, Alonso y Gómez, 2017). De hecho, Galicia ha sido la primera comunidad autónoma española en mostrar síntomas de cambio político. Así, la prematura emergencia de AGE en 2012, germen de Podemos en las elecciones europeas de 2014 (Fernández-Albertos, 2015), justifica la oportunidad del estudio de las bases electorales de dicha formación que, en 2016, terminaría por integrarse dentro de En Marea.

Siguiendo a Rokkan y Urwin (1983), un partido nacionalista es aquel en cuya agenda política está la defensa de un territorio distintivo dentro del Estado al que pertenece. De esta forma, es de esperar que la dimensión centro-periferia sea la principal en este tipo de partidos. En el caso de Galicia, si consideramos a AGE y En Marea como formaciones nacionalistas, tal y como sugiere su mensaje político, cabe esperar que los factores relacionados con el voto nacionalista en España — sentimiento nacional y preferencia territorial, principalmente- jueguen un papel determinante a la hora de que el elector muestre una mayor predisposición a votar a dichas formaciones en lugar de hacerlo por otras o abstenerse. Sin embargo, tal y como sugieren Scantamburlo, Alonso y Gómez (2017: 17), creemos que los nuevos partidos que han surgido tras la crisis económica de 2008 a nivel regional, pese a tener un discurso nacionalista, enfatizan principalemnte otros temas de competición política, tales como la igualdad económica y la regeneración democrática, dejando en un segundo plano las cuestiones territoriales que siguen siendo atendidas fundamentalmente por las formaciones nacionalistas tradicionales. Así, nuestra hipótesis sostiene que:

\footnotetext{
${ }^{5}$ Sirvan como ejemplos de este discurso marcadamente nacionalista el contenido del acuerdo programático de Anova y EU (enlace: https://es.scribd.com/doc/108618330/Programa-Electoral) en el que se explicita que uno de los objetivos es conseguir el autogobierno de Galicia. En esta misma línea camina el programa electoral de En Marea (enlace: https://enmarea.gal/programa/) en el que se reconoce el derecho del pueblo gallego a decidir cómo organizarse (p. 130).
} 


\section{Hipótesis 1. Las variables de preferencia por la organización territorial y de identidad nacional no resultan significativas a la hora de explicar el voto a AGE en 2012 y En Marea en 2016}

En las siguientes secciones exploramos 1) la evolución electoral del nacionalismo gallego y 2) las razones que están detrás de la emergencia de AGE y posteriormente de En Marea. Con ello, estaremos en condiciones de poder testar nuestra hipótesis.

\subsection{El voto nacionalista en las elecciones autonómicas gallegas}

El carácter de nacionalidad histórica y los hechos diferenciales como la lengua y la cultura propias explican que en Galicia haya existido un movimiento nacionalista que pronto se organizó en torno a partidos que acabaron teniendo representación parlamentaria autonómica y estatal. Sin embargo, no está de más señalar que a lo largo de su corta historia el nacionalismo gallego ha conocido la aparición, consolidación, escisión, confluencia y desaparición de numerosas formaciones políticas. Así, junto a los principales partidos de ámbito estatal, Alianza Popular / Partido Popular (AP/PP), Partido Socialista Obrero Español (PSOE) y Unión de Centro Democrático (UCD), han existido partidos nacionalistas y regionalistas con presencia en el Parlamento de Galicia.

En las diez elecciones autonómicas celebradas hasta la fecha, la historia de los partidos políticos galleguistas puede dividirse en tres etapas: una primera caracterizada por la atomización de la oferta partidista del nacionalismo gallego (1981-1989); una segunda en la que el grueso de este movimiento político se coordina en torno a las siglas del BNG (1993-2009); y una última fase en la que la oferta política nacionalista vuelve a fragmentarse parcialmente (2012-2016).

\section{Primera etapa (1981-1989): la atomización del nacionalismo gallego}

En las elecciones autonómicas que tuvieron lugar en la década de los ochenta (1981, 1985 y 1989), dentro del movimiento nacionalista y regionalista gallego tuvieron representación en el Parlamento de Galicia un importante número de partidos, entre los que cabe destacar Esquerda Galega (EG), Partido Socialista Galego (PSG), Coalición Galega (CG) y el BNG (Vilas Nogueira, 1992). En esta primera etapa, el espacio electoral nacionalista se va a caracterizar por una diversificación y dispersión en su oferta y por la continua crisis y rearticulación de los partidos nacionalistas (Máiz, 1996: 62).

EG fue un partido nacionalista de izquierdas, que obtuvo un único escaño en las elecciones autonómicas fundacionales de 1981 (con el 3,3 por ciento de votos a nivel regional), y que ocuparía su líder Camilo Nogueira Román. Aun aceptando el marco constitucional, esta organización política, que se nutría fundamentalmente de militantes obreros y sindicalistas, tenía como una de sus aspiraciones esenciales la autodeterminación de Galicia. Finalmente, terminó fusionándose en 1984 con el PSG, formando la coalición EG-PSG. 
El PSG ${ }^{6}$, por su parte, fue una formación política de ideología nacionalista y socialista. En las elecciones de 1981 concurrió en coalición electoral con el Bloque Nacionalista Popular Galego (BNPG) —el antecedente del BNG - y juntos obtuvieron el 6,15 por ciento de los votos y tres escaños (dos correspondientes al BNPG y uno correspondiente al PSG de Claudio González Garrido). Estos tres diputados fueron expulsados del Parlamento porque su ideología soberanista les impidió jurar lealtad a la Constitución Española. Cuando en 1982 se fundó el BNG, el PSG decidió integrarse en él; pero en 1983 volvió a abandonarlo. Finalmente, terminó por disolverse el partido, pues una parte de la militancia del PSG ingresó en el BNG como «Colectivo Socialista», mientras que el resto apostó por fusionarse con EG en 1984.

En las segundas elecciones autonómicas de 1985, el nuevo partido nacionalista de izquierdas PSG-EG, que también lideró Camilo Nogueira Román, obtuvo el 5,75 por ciento de los votos y tres escaños. Este partido nunca conseguiría de nuevo representación parlamentaria y, finalmente, tanto EG como PSG acabarían integrándose en el BNG con el nombre de Unidade Galega en 1995, consolidándose la coordinación del nacionalismo gallego en torno a unas mismas siglas (Lago, 2004).

Retomando las elecciones autonómicas de 1985, cabe destacar la irrupción de otro partido galleguista, CG, que desde posiciones ideológicas más moderadas, iba a resultar determinante para la gobernabilidad durante esa legislatura. CG fue un partido de ideología nacionalista gallega, menos radical en sus planteamientos en el eje centro-periferia, y de ideología de centro liberal. El partido se fundó en 1984 a partir del Partido Galeguista y, sobre todo, de barones y militantes procedentes de la recién extinta UCD, de forma que se orientó a capitalizar las redes clientelares de voto de esta formación, especialmente en las provincias orientales y en las zonas rurales (Máiz, 1996: 62; Rivera et al, 1998a: 301). Este partido, liderado inicialmente por Pablo González Mariñas, alcanzó su mayor éxito en las elecciones autonómicas de 1985, donde cosechó el 12,8 por ciento de los votos y once diputados en el Parlamento de Galicia. Asimismo, merece destacarse el hito de que CG fuese el primer partido nacionalista gallego en obtener representación parlamentaria en las Cortes Generales tras la restauración de la democracia, gracias al escaño conseguido por Senén Bernández Álvarez en las elecciones generales de 1986.

Ahora bien, la trayectoria del partido desde su entrada en el Parlamento gallego en 1985 fue ciertamente complicada, pues en su seno existían dos corrientes, una de carácter más progresista y otra de carácter más conservador (Máiz, 1996: 68). Ésta última fue la que se impuso en un primer momento, como evidencia el hecho de que los once diputados de CG se abstuviesen en la votación de investidura del popular Gerardo Fernández Albor, permitiendo su continuidad al frente de la Xunta de Galicia. 
Sin embargo, a principios de 1987, cinco diputados pertenecientes a CG encabezados por el propio Pablo González Mariñas, ejecutaron la escisión del sector más nacionalista y progresista del partido, creando el Partido Nacionalista Gallego (PNG). Esta nueva formación política acabaría resultando clave en la moción de censura contra el popular Fernández Albor.

Para comprender el éxito de esta moción de censura, hay que recordar, además, la importancia de uno de los primeros casos de transfuguismo político que adquirió relevancia en España. En este sentido, el diputado gallego Xosé Luis Barreiro presentó su dimisión como Vicepresidente de la Xunta, abandonó el grupo parlamentario popular, y arrastró consigo a otros cuatro diputados conservadores para la constitución de un partido fugaz: la Unión Demócrata Galega. La vida de este partido fue breve, y Barreiro y los suyos no tardaron en recalar en CG en 1987, formación política que acabaría nombrándole como secretario general. Fue desde esa plataforma desde donde Barreiro apoyó la moción de censura del PSOE contra AP, consiguiendo ser en el periodo de un año tanto el hombre fuerte de Fernández Albor y Vicepresidente de la Xunta con AP, a hacer lo propio en el gobierno encabezado por el PSOE de González Laxe.

Esta moción de censura, operada en septiembre de 1987, fue la primera de las que se han producido en la historia autonómica española que culminó con éxito. En ella, Gerardo Fernández Albor fue sustituido por el socialista Fernando González Laxe con el apoyo de los diputados pertenecientes a los tres partidos firmantes del Pacto dos Tilos (PSOE, CG, y PNG), además del PSG-EG, que renuncio a entrar en el Gobierno (Márquez, 2014: 254).

La moción de censura dio paso a la formación de un gobierno tripartito que se mantuvo en el poder durante los dos años y dos meses que restaban de legislatura, encabezado por el PSOE y escoltado por CG y el PNG. Esta fue, pues, la primera vez en la que el nacionalismo gallego alcanzaría posiciones de gobierno: de las 12 consejerías, 6 fueron ocupadas por miembros del PSOE, 4 de CG y 2 del PNG. Con todo, este gobierno de coalición no estuvo exento de inestabilidad, como demuestra el hecho de que el vicepresidente renunciase a su cargo en julio de 1988 y se produjese la consiguiente remodelación de gobierno, así como la existencia de nuevos casos de transfuguismo en cuatro diputados de partidos que formaban parte del gobierno (2 del PSOE y 2 del PNG) y que pasaron al Grupo Mixto del Parlamento (Márquez, 2014: 255).

Tras esta caótica legislatura, CG volvió a presentarse a las elecciones autonómicas de 1989, pero en esta ocasión experimentó un importante retroceso electoral. Así, en los que serían los últimos comicios en las que conseguiría representación, alcanzó un modesto 3,64 por ciento de los votos y dos diputados. 
¿Voto nacionalista? | José Rama Caamaño, Carlos Fernández Esquer, José Manuel Pantín Morado Correo

\section{Segunda etapa (1993-2009): la confluencia del nacionalismo gallego en torno al BNG}

En la que cabe calificar como segunda etapa del movimiento nacionalista en el sistema de partidos gallego (1993-2009), ésta se caracterizó por reducirse a tres el número de partidos con representación parlamentaria (PP, PSOE y BNG); y, sobre todo, por la reducción de la oferta partidista en el espacio nacionalista gallego a través de un proceso de coordinación electoral en torno al BNG (Lago, 2004). Este partido se situó como fuerza política nacionalista preeminente durante dos décadas, y en la que progresivamente acabarían integrándose otros muchos partidos (CG, PNG y PSG-EG) y recalando algunos de los «pesos pesados» del nacionalismo gallego, como Camilo Nogueira o Rodríguez Peña (Rivera et al., 1998a: 304).

Puede caracterizarse al BNG como una organización política de carácter nacionalista y progresista, cuya voluntad fue desde un principio la de aglutinar al conjunto de corrientes del nacionalismo gallego, como evidencia su lema fundacional: Por un frente amplo de unidade nacionalista.

En las primeras elecciones autonómicas de 1981, el precedente directo del BNG, el Bloque Nacional-Popular Galego, concurrió en forma de coalición con el Partido Socialista Galego (BNPG-PSG), consiguiendo tres escaños, dos de ellos pertenecientes al BNPG. En las siguientes elecciones autonómicas de 1985, y tras la génesis propiamente dicha del BNG en 1982 (Vilas Nogueiras y Fernández Baz, 2004: 203-206), esta fuerza política consiguió un único escaño, el de su líder histórico Xosé Manuel Beiras. Ese sería su peor resultado electoral hasta nuestros días, pues en adelante siempre ha tenido un mayor éxito electoral que le ha permitido formar grupo parlamentario en todas las ocasiones (5 escaños en 1989; 13 en 1993; 18 en 1997; 17 en 2001; 13 en 2005; 12 en 2009; 7 en 2012; y 6 en 2016).

El salto cualitativo del BNG se produjo en las elecciones de 1993, donde avanzó de 5 a 13 escaños. Esto se debió al proceso de coordinación en torno a sus siglas de los principales partidos nacionalistas gallegos. Proceso que se vio acelerado por la decisión estratégica del PP de incrementar la barrera electoral del 3 al 5 por ciento, para evitar la representación de fuerzas nacionalistas minoritarias, llegando a ser incluso superior el efecto "psicológico» de la reforma que el «mecánico» (Lago, 2004: 47; Rama y Fernández, 2017).

Así, el BNG ha experimentado una paulatina evolución ideológica, por la que habría ido moderando su discurso desde finales de los años ochenta y principios de los noventa, con vistas a mejorar su adaptación a la competición partidista y así poder conseguir un mayor poder político e incluso aspirar a gobernar (Máiz, 1996; Rivera et al., 1998a; Lago, 2004: 48-55; Gómez-Reino, 2006, 2009; Elias, 2009). De este modo, frente a la dispersión originaria del voto nacionalista, emergió una paulatina concentración de fuerzas buscada por la clase política. Las diversas familias nacionalistas, con su diversidad de matices, dieron origen a un proceso tortuoso de confluencia (Rivera et al., 1998b: 325). Se trató de una transformación en la que prácticamente desapareció el nacionalismo de 
centro-derecha, en parte por la ocupación de dicho espacio por el PP de Fraga que acentuaría los elementos de galleguización de su discurso (Máiz, 1996: 70); y en parte por el abandono del BNG de sus iniciales posiciones radicales, como manera de construir un frente nacionalista que aglutinase tanto a los colectivos de la izquierda más reivindicativa como a aquellos que defendían posturas ubicadas en el centro ideológico, esto es, al nacionalismo más moderado que en su momento había votado masivamente a CG (Rivera et al., 1998a: 304).

Cabe destacar los comicios de 1997, en los que el BNG recibió cerca de 400.000 votos (un 25 por ciento del total) que le sirvieron para hacerse con 18 escaños. Se produjo así por vez primera el sorpasso sobre el PSOE, que convirtió al BNG en el principal partido de la oposición, consiguiendo por primera vez en la historia autonómica gallega que una fuerza nacionalista se situase como alternativa real de gobierno a un partido de ámbito estatal (Rivera et al., 1998a: 303). De forma que en las elecciones de 1997 el voto nacionalista encontró, definitivamente, un partido capaz de atraer a electorados situados en diversos sectores del eje izquierda-derecha, gracias a una estrategia de moderación ideológica que avanzó hacia posiciones menos radicales tanto en el cleavage izquierda-derecha como en el centro-periferia (Rivera et al., 1998b: 327-328). En las elecciones de 2001, el BNG repitió sus buenos resultados, superando ligeramente en votos al PSOE y consiguiendo ambos el mismo número de diputados.

A pesar de que en las elecciones de 2005 el BNG sufrió un retroceso hasta los 13 diputados, el hecho de que el PP se quedase a un solo escaño de la mayoría absoluta situó a los nacionalistas en una posición privilegiada para propiciar la alternancia en el gobierno (Pallarés y Lago, 2005). Así, en la VII legislatura del Parlamento de Galicia (2005-2009) se produjo el histórico bipartito gallego entre el PSOE y BNG, por el que ambos partidos sellaron un acuerdo para gobernar conjuntamente bajo la presidencia de Emilio Pérez Touriño y la vicepresidencia de Anxo Quintana. De las trece consejerías que conformaron el gobierno, ocho correspondieron al PSOE y las otras cuatro y la vicepresidencia con cartera fueron a parar al BNG (Márquez, 2014: 259). Este bipartito acabo con la hegemonía del PP hasta ese momento en el sistema de partidos gallego e interrumpió el ciclo de cuatro mayorías absolutas consecutivas de los populares (1989, 1993, 1997, 2001). Aunque este gobierno puede considerarse estable, pues agotó la legislatura y no experimentó ninguna remodelación, sin embargo, las dinámicas intracoalicionales no estuvieron exentas de tensión. Especialmente en el último año de legislatura, en el que ambos partidos parecieron desarrollar estrategias de diferenciación competitiva en el seno del gobierno, con vistas a los futuros comicios (Márquez, 2014).

El último dato destacable del BNG es que ha obtenido representación parlamentaria en el Congreso de los Diputados de forma continuada en las cinco elecciones generales celebradas desde 1996 hasta 2011. En todos esos comicios el BNG ha conseguido hacerse con 2 diputados, excepto en las elecciones generales de 2000, año en que superó los 300.000 sufragios y obtuvo 3 escaños. 


\section{Tercera etapa (2012-2016): el retorno (parcial) a la dispersión del nacionalismo gallego}

En la última etapa para el nacionalismo gallego, que comienza con las elecciones de 2012, se produce un nuevo fraccionamiento de la oferta partidista en el espectro político nacionalista. Ahora bien, esta nueva fase no supone ni mucho menos un retorno al escenario que presentaba el nacionalismo en las primeras elecciones de los años ochenta, al menos por dos motivos. El primero de ellos es que no existen tantos partidos nacionalistas gallegos con representación parlamentaria, sino que van a ser dos (BNG y AGE en 2012 y En Marea en 2016) y, además, con una representación importante y grupo parlamentario propio. El segundo motivo que diferencia este nuevo ciclo del nacionalismo gallego respecto a la primera etapa es que tanto AGE como En Marea van a ser coaliciones electorales amplias, que van a estar integradas no sólo por el partido nacionalista de referencia (AnovaIrmandade Nacionalista), sino que también van a incluir a partidos más a la izquierda del PSOE, como EU y Podemos.

En las elecciones autonómicas de 2012 concurrió Alternativa AGE, una coalición política que incluyó a una importante escisión del BNG liderada por Xosé Manuel Beiras, llamada Anova-Irmandade Nacionalista, y otras formaciones de ámbito estatal como EU-IU y EquoGalicia. Para entender esta alianza, hay que hacer referencia a la crisis interna desencadenada en la XIII Asamblea Nacional del BNG, celebrada en enero de 2012, en la que se formaron corrientes críticas internas y que se saldó con un importante número de partidos escindidos (Blanco Casais, 2013). Dicho lo cual, el éxito de la coalición AGE fue rotundo, pues recibió más de 200.000 votos; y lo que es más importante, irrumpió en el Parlamento gallego con 9 escaños, dos más que el BNG.

AGE sería el preludio de En Marea, una nueva coalición que concurrió a las últimas elecciones de 2016, formada por Anova, Podemos, Esquerda Unida y diferentes agrupaciones ciudadanas que ya se presentaron con notable éxito en las elecciones municipales de mayo de 2015. En estos últimos comicios de 2016, En Marea obtuvo un mayor número de votos que el PSOE, pese a que finalmente ambas organizaciones políticas terminarían recibiendo 14 escaños. Por su parte, el BNG continuó con su descenso en el número de escaños, reteniendo tan solo 6 diputados.

La Figura 1 muestra la evolución del porcentaje de votos de las distintas formaciones que han obtenido representación desde 1981 hasta 2016 en el Parlamento de Galicia, y sirve como resumen del apoyo cosechado por los partidos nacionalistas gallegos a lo largo de estos años. 
Figura 1. Porcentaje de votos en las elecciones autonómicas gallegas, 1981-2016

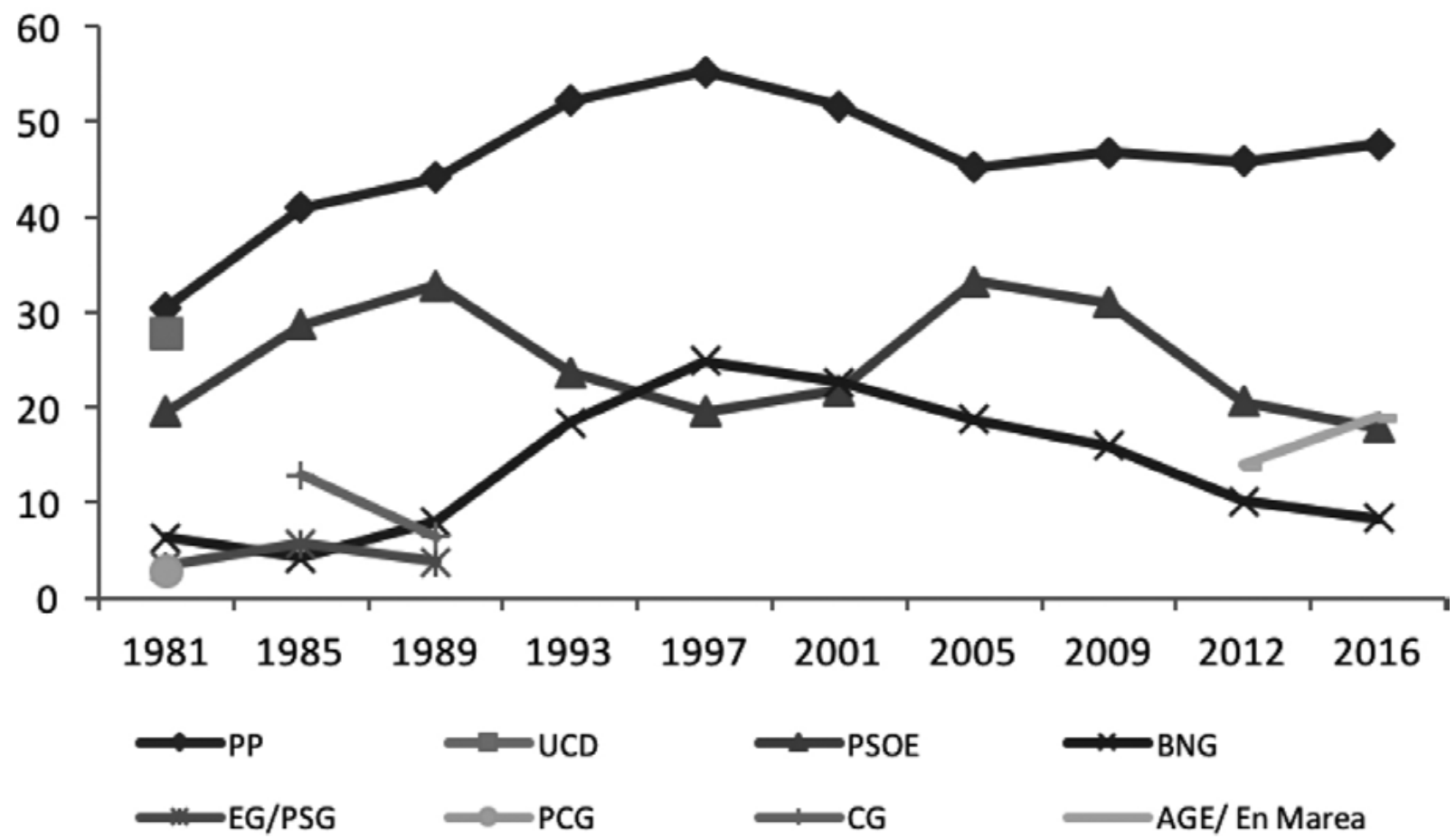

Fuente: Rama y Fernández Esquer (2017).

\subsection{Los efectos de la XIII Asamblea Nacional del BNG en el nacionalismo gallego}

La XIII Asamblea Nacional del BNG se proponía debatir el futuro de un partido que recientemente, y por primera vez en su historia, había participado en el gobierno de la Xunta de Galicia (2005-2009). Durante esos años, el vicepresidente de la Xunta, Anxo Quintana, era el referente de un sector moderado próximo a la socialdemocracia, pero vigilado muy de cerca por el sector más radical, de ideología comunista y nacionalista, representado principalmente por la Unión do Pobo Galego (UPG) y el Movemento Galego ao Socialismo (MGS). En consecuencia, la pérdida de votos que en las elecciones de 2009 había sufrido el BNG fue interpretada por estas corrientes como un abandono de los ideales durante el desempeño de la acción de gobierno ${ }^{7}$.

En la Asamblea de Amino la candidatura promovida por la UPG, Alternativa pola Unidade (ApU), contaba con el apoyo de la mayoría de los militantes del partido, especialmente de los más movilizados. De ahí que la participación sirviese como termómetro predictor de los apoyos a la candidatura liderada por Xosé Manuel Beiras y sus seguidores organizados en el Encontro Irmandiño (EI), aliados de Máis Galiza (+GZ) -la segunda corriente más numerosa del partido después de la UPG—, que presentaban como candidato al socialdemócrata Carlos Aymerich. Esta corriente reclamaba una mayor lealtad dentro del partido y apoyar a éste con paciencia en su trabajo institucional ${ }^{8}$.

\footnotetext{
7 Véase la crónica en El País del 29 de enero de 2012 «La UPG pondrá rostro al Bloque».

${ }^{8}$ Véase la crónica en El Mundo del 29 de enero de 2012 «El Bloque Nacionalista Galego, un partido "dividido en dos"».
} 
Finalmente, tras el recuento de votos la Asamblea nombró a un nuevo candidato a la Xunta de Galicia y a un nuevo portavoz nacional, ambos de la ApU y ambos por escaso margen de victoria, 2.123 papeletas frente a $1.823^{9}$. La impotencia de las corrientes alternativas a la UPG, que aspiraban a «modernizar» el partido, se vería reflejada en sus posteriores declaraciones, en las que llegarían a afirmar que los votantes del BNG estaban muy alejados de las tesis de la UPG. Según Beiras, el BNG debía atraer a aquellos que se habían movilizado pocos meses antes en las plazas a través del 15- $\mathrm{M}^{10}$.

Los rumores de escisión y división del nacionalismo, que fueron una amenaza que planeó antes y durante el Congreso de Amio, se hicieron realidad transcurridas tan solo dos semanas. El carismático líder nacionalista, Xosé Manuel Beiras, terminaría por darse de baja del partido que contribuyó a fundar — desde el mitin de Riazor (1982) — treinta años atrás. El BNG perdía así a su referente histórico ${ }^{11}$. Asimismo, la corriente $+\mathrm{GZ}$ seguiría los pasos de Beiras. A excepción de Carlos Aymerich que permaneció en el BNG ${ }^{12}$, el resto de compañeros de la facción fundó Compromiso por Galicia (CxG), que pasaría a liderar Xoán Bascuas³.

Poco tiempo después, los Irmandiños abandonan también el BNG con la intención de sumarse a otras formaciones y movimientos de izquierda socialista y ecologista ${ }^{14}$. Las reuniones y asambleas en torno a este proyecto fueron llamadas Novo Proxecto Común, y acabaron por fundar en el mes de julio Anova-Irmandade nacionalista ${ }^{15}$. Con las elecciones autonómicas gallegas en el horizonte, Beiras comenzó a celebrar asambleas y mítines por toda Galicia. En sintonía con el 15-M, desplazó el discurso nacionalista para hacer suya la lucha contra los recortes, logrando una gran asistencia a sus mítines, conectando con votantes jóvenes y urbanos con la ayuda de Pablo Iglesias Turrión, asesor de campaña de IU en la coalición ${ }^{16}{ }^{17}$. Así, en las elecciones autonómicas de 2012, AGE cosecharía un resultado electoral sorprendente, superando al BNG en 4 escaños.

Por su parte, en el seno del BNG los debates internos sobre proyectos y estrategias políticas acabaron por erosionar a una organización que mantuvo a los mismos líderes desde su fundación hasta la Asamblea de Amio. Todo esto desencadenaría enfrentamientos per-

\footnotetext{
9 Véase la crónica en La Voz de Galicia del 30 de enero de 2012 «La asamblea del Bloque deja el frente dividido en dos mitades".

${ }^{10}$ Véase entrevista del programa «Otra vuelta de tuerka». Pablo Iglesias con Xosé Manuel Beiras en la red social YouTube.

11 Véase el reportaje en El Español del 9 de agosto de 2016 «Adiós a Beiras: el león blanco del nacionalismo gallego deja de rugir».

12 Véase el reportaje en ABC del 17 de septiembre de 2012 «Huérfanos de un padre «traidor»».

${ }_{13}$ Véase la noticia del Correo Gallego del 16 de diciembre de 2012 «Xoán Bascuas, elegido Secretario Xeral de CxG».

${ }^{14}$ Véase la noticia en La Vanguardia del 14 de julio de 2012 «Beiras cree que el referente del nuevo proyecto nacionalista, que tiene "las puertas abiertas", debe "ser colectivo"».

15 Véase la noticia en Europa Press del 11 de septiembre del 2012 «Anova e IU se presentarán como “Alternativa Galega de Esquerda'».

${ }^{16}$ Véase el reportaje en El Confidencial del 24 de septiembre de 2017 «El soberanista gallego que susurra al oído de Pablo Iglesias la estrategia ante el 1-O».

17 Véase el reportaje en La Opinión A Coruña del 28 de mayo del 2014 «Beiras: Sintonizo con Pablo Iglesias, es un pionero de la nueva cultura política».
} 
sonales entre «históricos» incapaces de resolver sus diferencias, especialmente Beiras y Francisco Rodríguez ${ }^{18}$, este último referente ideológico de la UPG ${ }^{19}$. El BNG continuó su proyecto «frentista» con la UPG aún más poderosa y con una corriente socialdemócrata que seguía intentando modernizar el partido, con el mismo Aymerich como líder pero descapitalizado por la fuga de militantes y referentes.

El fracaso del BNG en las elecciones autonómicas de octubre de 2012, con Francisco Jorquera como candidato y Guillerme Vázquez como portavoz nacional, evidenció el diagnóstico de los escindidos en la Asamblea de Amio. Más tarde, el BNG, ahora bajo claro control de la UPG, nombraría un nuevo portavoz nacional, el Catedrático de Economía Xavier Vence, quien mantuvo la exigencia y objetivo de la UPG (la autodeterminación e independencia del pueblo gallego), a la par que intentaba pactar la unión de las fuerzas nacionalistas, si no dentro del BNG, en coalición con Anova y otras formaciones pequeñas. El fracaso de estas negociaciones para unir al nacionalismo, sin contar con otras fuerzas de ámbito estatal como IU y movimientos no nacionalistas como En Marea, imposibilitó el acuerdo y el aval de la UPG.

Por su parte, el proceso de construcción de En Marea arranca en las elecciones municipales de 2015. Después de la irrupción de Podemos a nivel estatal en las elecciones al Parlamento Europeo de mayo de 2014, las elecciones municipales fueron la primera oportunidad de Podemos para demostrar que era una fuerza importante en España. La experiencia de Pablo Iglesias y Xosé Manuel Beiras con la coalición de Anova sirve de modelo para las elecciones municipales en las principales ciudades gallegas, donde los líderes pueden controlar las candidaturas y evitan extender la fórmula a los pequeños ayuntamientos.

Las candidaturas en la provincia de A Coruña formadas por Podemos, Anova, IU y otros movimientos de izquierda no nacionalista (Marea Atlántica en A Coruña, Compostela Aberta y Ferrol en Común), consiguen hacerse con la alcaldía de las ciudades sin la participación del BNG, partido que intenta presentar una candidatura abierta a otras organizaciones nacionalistas, con la marca BNG-Asambleas Abertas. La perseverancia en su estrategia les lleva a continuar perdiendo apoyos.

Las malas experiencias del BNG acudiendo en solitario sin integrarse en las candidaturas de unidad popular Podemos-En Marea-Anova-EU, reactivan a los críticos dentro del Bloque para coaligarse con el nuevo partido político liderado por los alcaldes de A Coruña y Santiago y el propio Beiras. El portavoz nacional, Xavier Vence, partidario de la integración, presenta su dimisión y se da de baja en el partido tras el fracaso de la candidatura nacionalista, NOS-Candidatura Galega a las elecciones generales de $2015^{20}$, donde pierde sus dos diputados y la representación en el Congreso de los Diputados que mantenía desde 1996.

\footnotetext{
18 Véase la noticia en El Mundo del 24 de enero del 2012 «Beiras: 'Francisco Rodríguez siempre está en la sombra, va a durar más que Franco'».

${ }^{19}$ Véase la noticia en Faro de Vigo del 16 de junio del 2012 «El adiós de Francisco Rodríguez abre un relevo generacional en la UPG».

${ }^{20}$ Véase la noticia en La Voz de Galicia del 26 de febrero del 2016 «Vence insiste en reclamar una refundación a fondo del BNG para frenar su declive».
} 
En las elecciones autonómicas de septiembre de 2016, En Marea se presenta con un candidato no nacionalista, el Juez del Tribunal Superior de Xustiza de Galicia, Luís Villares, representante de los partidos que integra: En Marea de origen urbano y formado por miembros de la sociedad civil alineados con los movimientos progresistas de izquierda contra los recortes; Anova de izquierda nacionalista; junto a Podemos e IU, organizaciones de izquierda estatal.

A su vez, el BNG elige en la Asamblea de febrero de 2016 a una nueva candidata y portavoz, Ana Pontón, con un perfil nacionalista más mediático que los anteriores portavoces y en sintonía con el mensaje social y las organizaciones asamblearias, pero contraria a aliarse de cara a las elecciones autonómicas con partidos no nacionalistas. Pontón consigue amortiguar la pérdida de votos del BNG, que valora como un éxito perder sólo un diputado en la cámara gallega. La asamblea de 2016 provoca más bajas de militantes en el partido (cuenta con la mitad desde la Asamblea de Amio de 2012), y de referentes socialdemócratas como Anxo Quintana y Carlos Aymerich, dejando el BNG bajo el dominio absoluto de la UPG.

En resumen, podríamos calificar esta tercera etapa del nacionalismo gallego como un periodo confuso. Tras la Asamblea de Amio en la que el BNG perdió su esencia como bloque de piezas (partidos) nacionalistas quedándose meramente con la presencia de la UPG, el surgimiento de AGE en 2012 y En Marea en 2016 estaría lejos de poder justificarse como el resultado de la fragmentación del nacionalismo gallego. Más bien, todo apunta a que el elemento nacionalista habría quedado soterrado bajo un proceso mayor, relacionado con cierto desalineamiento (descontento de los votantes con los partidos establecidos) y realineamiento electoral ${ }^{21}$ (importancia de nuevos temas que, por su relevancia, actúan como elementos decisorios del voto) por el que nuevas formaciones emergieron ${ }^{22}$, en un sistema de partidos consolidado como el sistema gallego.

\section{MÉTODOS Y DATOS}

Asumiendo que los partidos nacionalistas reciben el voto de electores que muestran un sentimiento nacionalista, en este caso, que se sienten más gallegos que españoles, o que son más favorables a un Estado descentralizado que a uno en el que el grueso de las competencias se ejerza desde el poder central, nos proponemos comprobar el efecto de estas variables en la probabilidad de votar a AGE en 2012 y a En Marea en las elecciones de 2016. Nuestra hipótesis sostiene que estas variables no resultarán significativas a la hora de explicar el voto a ambos partidos. Para comprobarlo, utilizamos las encuestas postelec-

\footnotetext{
${ }^{21}$ Para una información más en detalle sobre los conceptos de desalineamiento y realineamiento electoral, ver la obra Electoral Change in Advanced Industrial Democracies. Realignment or Dealignment? (Dalton et. al. 1984). ${ }^{22}$ Para ver el surgimiento de nuevos partidos debido a los procesos de desalineamiento y realineamiento electoral, consultar la obra de Harmel y Robertson (1985).
} 
torales autonómicas del Centro de Investigaciones Sociológicas (CIS): los estudios 2.963 y 3.155 para los comicios de 2012 y 2016 , respectivamente.

Uno de los mejores métodos para testar el efecto de estas variables en el voto es la regresión logística. Así, nuestra variable dependiente toma valor 1 cuando el recuerdo de voto es haber confiado electoralmente en AGE en 2012 y haber hecho lo propio por En Marea en 2016, y valor 0 cuando el entrevistado declara haber votado a otra formación o haberse abstenido.

Introducimos dos tipos de variables como elementos de control. Por un lado, como en la mayoría de investigaciones sobre comportamiento político y electoral, controlamos por las características sociales y demográficas de los individuos: el género (variable dicotómica en la que 1 = mujer y 0 = hombre); el nivel educativo (variable nominal en la que la categoría de "sin estudios o estudios primarios» actúa como categoría de referencia sobre la que comparamos el efecto en la variable dependiente de tener «educación secundaria», «formación profesional» y «educación universitaria», introducidas como variables dicotómicas, $0=$ ausencia del atributo y 1 = presencia del atributo); el tamaño del municipio que, al igual que la variable de educación, introducimos como una serie de variables dicotómicas que toman como referencia la categoría de un tamaño de hábitat inferior o igual a 2.000 habitantes; la frecuencia de asistencia a oficios religiosos (variable dicotómica en la que 1 = más de una vez al mes y 0 = menos de una vez al mes o ninguna); y la situación laboral del entrevistado (variable dicotómica en la que 1 = desempleado y 0 = no desempleado). Y, por otro lado, controlamos por variables de tipo político y económico: la ideología (es una variable continua que se mueve en una escala de 1, izquierda a 10, derecha); la valoración actual de la situación económica personal y en Galicia (es una variable dicotómica en la que 1 = positiva y 0 = negativa); y la valoración actual de la situación política en España y Galicia (es una variable dicotómica en la que 1 = positiva y 0 = negativa).

Como variables independientes principales para explicar el voto a AGE en 2012 y En Marea en 2016, hemos seleccionado la escala de nacionalismo (es una variable continua que oscila entre el 1, mínimo sentimiento nacionalista, y el 10, máximo sentimiento); la preferencia por la organización territorial del estado (es una variable nominal en la que hemos establecido como categoría de referencia «un estado más centralizado» y hemos introducido como variables dicotómicas la preferencia por un «Estado organizado como el actual» y la preferencia por «una mayor descentralización del Estado»); y el sentimiento nacional (es una variable nominal que toma como categoría de referencia el «sentimiento únicamente español o más español que gallego» y en la que hemos introducido como variables dicotómicas «sentimiento igual gallego que español» $\mathrm{y}$ «sentimiento más gallego que español»). El conjunto de variables de control e independientes se encuentran resumidas en la Tabla 1 en el ANEXO, mostrando el número de observaciones, la media, la desviación típica, el máximo y el mínimo. 


\section{RESULTADOS}

La Tabla 2, en el ANEXO, muestra dos modelos de regresión logística. En el Modelo 1 la variable dependiente es el recuerdo de voto a AGE frente a abstenerse o votar por otro partido en las elecciones autonómicas de 2012 y, en el Modelo 2, la variable dependiente es el recuerdo de voto a En Marea frente a abstenerse o votar por otro partido en las elecciones autonómicas de 2016. Para hacer más sencilla la interpretación de los resultados, recurrimos a la representación gráfica de las probabilidades de voto a AGE y En Marea en función de las dos principales variables independientes de nuestro modelo: el sentimiento nacional y la preferencia por la organización territorial (Santana y Rama, 2017).

Figura 2. Probabilidad de votar a AGE en las elecciones autonómicas de 2012 en función del sentimiento nacional y de la preferencia de la organización territorial del Estado.
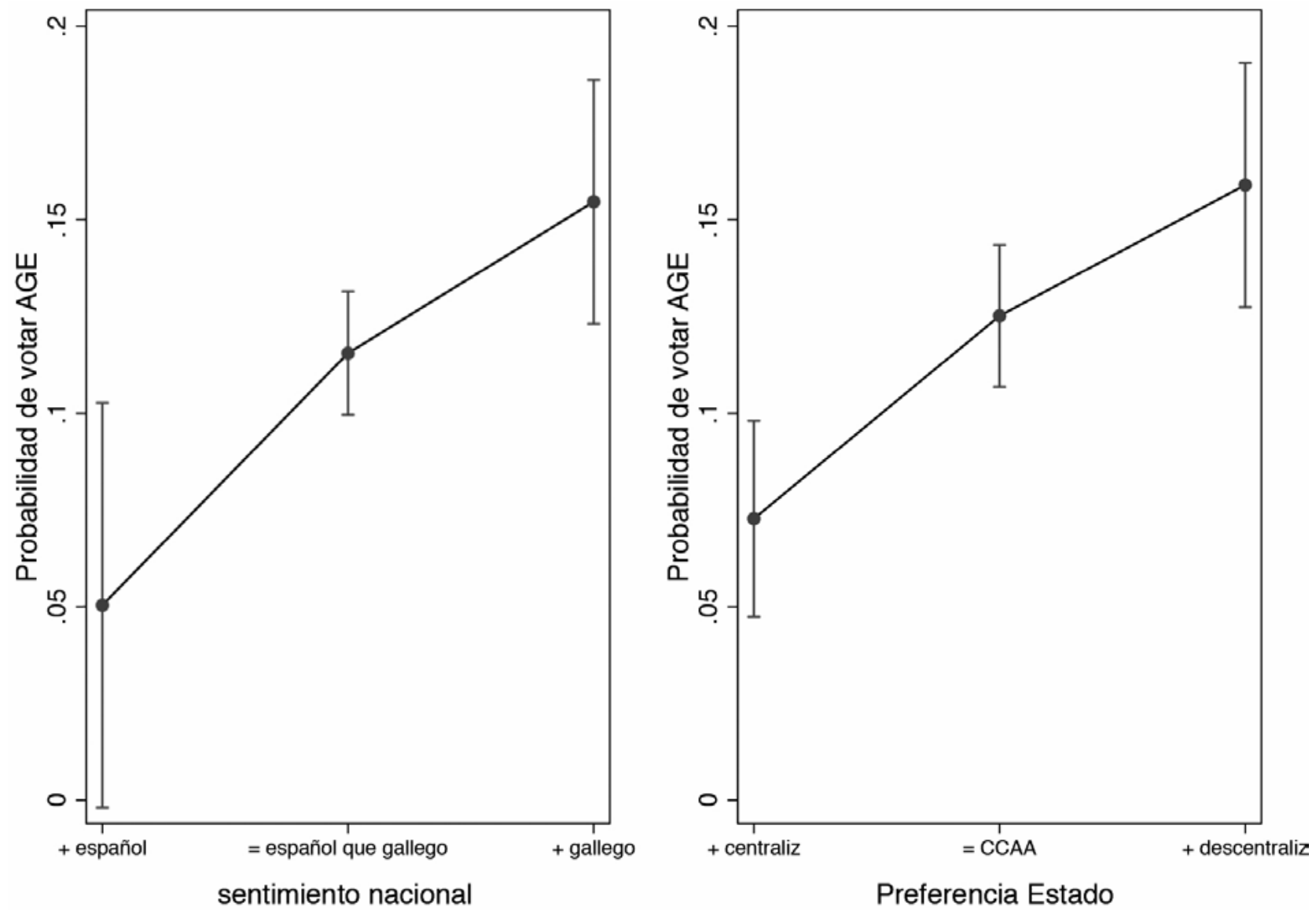

Fuente: elaboración propia en base a los datos del CIS 2963.

La Figura 2, en la imagen de la izquierda, muestra la probabilidad de votar a AGE en función del sentimiento nacional, controlando por el resto de variables del modelo. El gráfico muestra cómo la probabilidad es mayor para aquellos que se sienten más gallegos que españoles, aunque no hay diferencias estadísticamente significativas entre los que se sienten más gallegos que españoles y los que se sienten tan gallegos como españoles (diferencias que sí existen entre los que se sienten más gallegos que españoles y aquellos que solo se sienten 
españoles o más españoles que gallegos). Por otro lado, la imagen de la derecha ilustra las probabilidades de votar a AGE en función de la preferencia por la organización territorial del estado. En este caso, las probabilidades de votar por la coalición formada por Anova-EU son mayores entre aquellos que están a favor de una mayor descentralización del estado. Existen diferencias significativas entre estos votantes y aquellos que están a favor de un estado más descentralizado, los cuales mostrarían una menor propensión a votar por AGE. En este sentido, parecería que los electores de la formación que lideró Beiras se diferenciarían del resto de votantes por su sentimiento nacionalista gallego, lo que nos haría situar a AGE como una formación cuyas bases electorales son esencialmente nacionalistas.

Figura 3. Probabilidad de votar a En Marea en las elecciones autonómicas de 2016 en función del sentimiento nacional y de la preferencia de la organización territorial del Estado
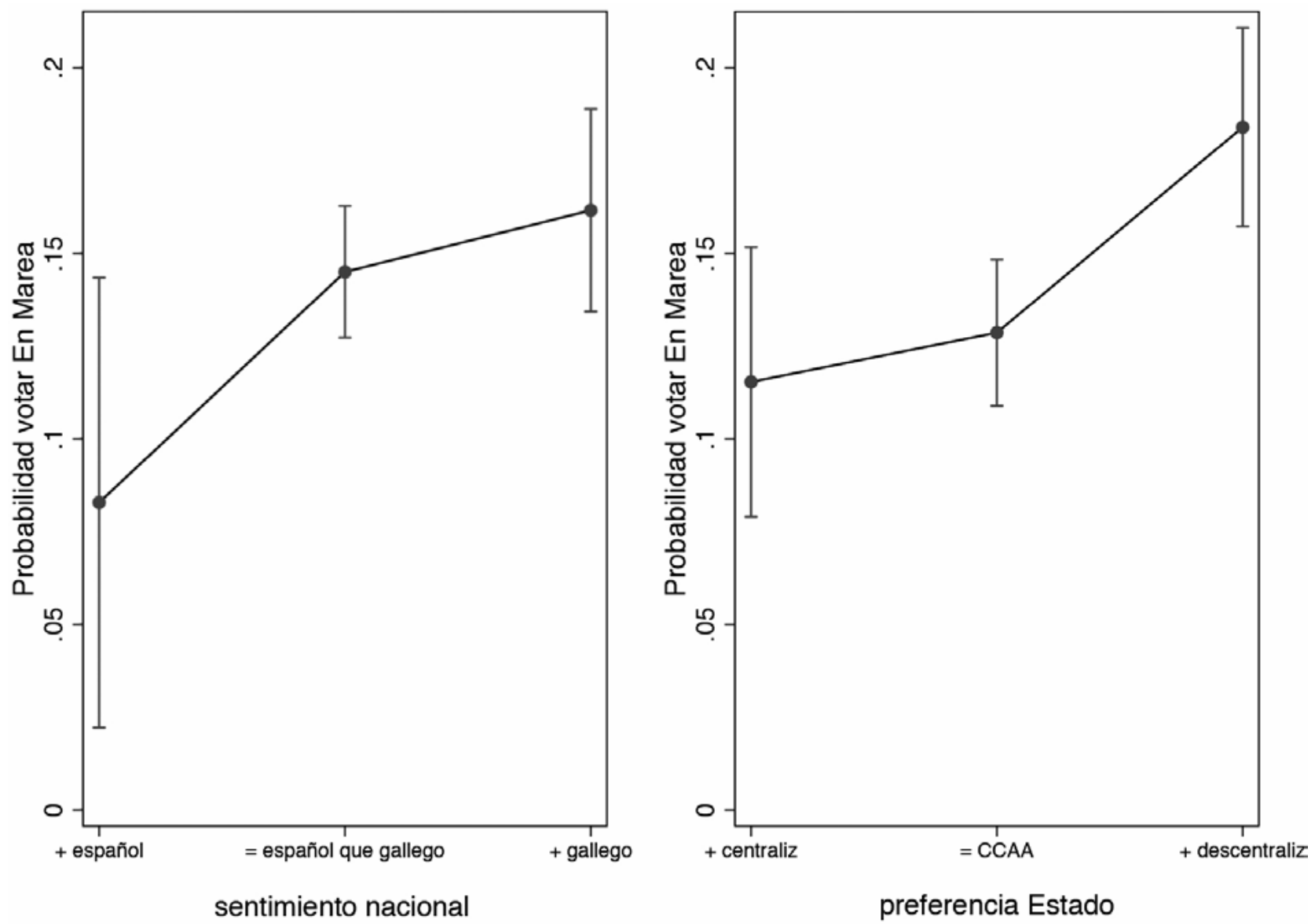

Fuente: elaboración propia en base a los datos del CIS 3155.

La Figura 3 ilustra la misma relación de variables que la Figura 2, pero para el caso de En Marea. Ambas imágenes, izquierda y derecha, muestran como no existen diferencias estadísticamente significativas ${ }^{23}$ entre electores que se sitúan en las distintas categorías de

${ }^{23}$ Como podemos observar en el gráfico, los intervalos de confianza se solapan en todas las categorías de nuestras dos variables independientes. Para más información sobre la interpretación de los gráficos ver Santana y Rama (2017: 172 y siguientes). 
nuestras variables independientes: sentimiento nacional y preferencia por la organización territorial del estado. Así, ni la preferencia de un estado más descentralizado, ni el sentirse más gallego que español, ayudan a explicar que un elector termine votando por En Marea en lugar de no votar o de hacerlo por otra formación. De esta forma, confirmaríamos que los votantes de la coalición formada principalmente por Anova, EU y Podemos, no destacan por ser aquellos con un sentimiento más nacionalista. Ninguna de las variables explicativas principales resulta estadísticamente significativa ${ }^{24}$, algo que si ocurría en el caso de AGE. Los electores de En Marea, como muestra la Tabla 2, son en su mayoría hombres, con un nivel educativo alto y que viven en zonas urbanas, un perfil muy similar al de los votantes de Podemos. Además, se situarían más a la izquierda que el resto de votantes y muestran un sentimiento negativo sobre la situación política española (Fernández Albertos, 2015).

Las Figuras 2 y 3 vendrían a confirmar la heterogeneidad del nacionalismo en Galicia en la tercera etapa. Así, mientras que los votantes de AGE muestran un perfil nacionalista (se sienten más gallegos que españoles y están a favor de un estado más descentralizado), los de En Marea no se diferencian del resto de electores en estas variables, que no resultarían decisivas para votar a la coalición en la que se integró Podemos. Así, nuestra hipótesis quedaría confirmada, pero sólo parcialmente: se cumple para En Marea, pero no aplica para AGE, coalición en la que el peso electoral estuvo del lado de los nacionalistas de Anova, no olvidemos, antes integrados dentro del BNG.

\section{CONCLUSIONES}

La emergencia de AGE y En Marea en las recientes elecciones autonómicas gallegas de 2012 y 2016, respectivamente, podría entenderse como una nueva etapa del nacionalismo gallego. Sin embargo, el contexto de cambio en el sistema de partidos que sobre todo a partir de 2015 vivió el panorama político español a nivel nacional, unido a que tanto AGE como En Marea son el resultado de coaliciones electorales de formaciones muy diversas, hace que nos cuestionemos su naturaleza como partidos estrictamente nacionalistas.

Desde 1981 el nacionalismo gallego ha atravesado varias etapas, caracterizadas por la mayor o menor fragmentación partidista, así como por la orientación política de las formaciones nacionalistas (con posiciones que van desde la radicalidad, pasando por el progresismo hasta llegar a otras de carácter más moderado). Desde 1993 hasta 2009, el BNG consiguió aglutinar a la gran mayoría de movimientos galleguistas en lo que constituyó un amplio frente nacionalista. Durante estos años el Bloque conseguiría en varias elecciones superar en votos y escaños al PSdeG, llegando al gobierno autonómico junto a los socialistas en los comicios de 2005. Además, el nacionalismo gallego en manos del BNG consegui-

\footnotetext{
${ }^{24}$ La Tabla 3 en el ANEXO replica los modelos de regresión logística de la Tabla 2 pero utilizando como variable dependiente el voto al BNG en 2012 y 2016 (1) frente al voto a otras formaciones o la abstención (0). Las probabilidades de que un elector termine por dar su apoyo al BNG son mayores entre aquellos que se consideran más nacionalistas y entre los que prefieren un estado más descentralizado.
} 
ría de forma ininterrumpida representación en el Congreso de los Diputados entre las elecciones de 1996 y 2011.

La XIII Asamblea Nacional del BNG, celebrada en 2012, fue el punto de inflexión que condicionaría el cambio en las dinámicas de competición electoral de los partidos gallegos. Como resultado de dicha Asamblea, el BNG tuvo que enfrentarse a la escisión de varias de sus facciones internas. Estas facciones terminarían por configurar nuevos partidos, entre ellos AGE, que habrían de marcar un antes y un después en la historia del nacionalismo gallego. Sin embargo, tal y como hemos demostrado en estas páginas, existen diferencias notables en las bases electorales de AGE y En Marea. Mientras que los electores de AGE parecen guardar semejanzas con los del BNG, los de En Marea comparten en lo sustancial el perfil de los electores de Podemos, una de sus formaciones electorales principales.

Con ello, parecería claro que, al menos en lo que se refiere a las bases electorales, en las últimas elecciones autonómicas fue sólo el BNG el partido capaz de atraer a aquellos votantes con un sentimiento identitario más galleguista (las probabilidades de que este tipo de votantes diese su apoyo al BNG frente a otra formación resultó positiva y estadísticamente significativa, como muestra la Tabla 3 en el ANEXO).

Con los resultados de este estudio contribuimos a enriquecer la clasificación de los nuevos partidos que recientemente han surgido en la arena electoral autonómica en España. En este sentido, Podemos optó en las recientes elecciones autonómicas por presentarse en confluencia con formaciones regionalistas (caso de Catalunya-En Comú Podem en Cataluña o En Marea en Galicia) en algunas comunidades con sentimientos nacionalistas arraigados. Nuestros hallazgos enfatizan la necesidad de cuestionarse cuáles son los principales factores explicativos del voto a los nuevos partidos regionalistas que han surgido tras la grave crisis económica de 2008. Los nuevos temas que suscitan interés a los votantes, tales como la regeneración de la democracia o la lucha contra la corrupción, podrían tener un mayor peso a la hora de explicar el apoyo a los nuevos partidos regionalistas, desplazando la que hasta ahora había sido la dimensión de competición política principal para este tipo de partidos: la dimensión centro-periferia.

\section{REFERENCIAS BIBLIOGRÁFICAS}

Adams, J., Clark, M., Ezrow, L., Glasgow, G. (2006). Are Niche Parties Fundamentally Different from Mainstream Parties? The Causes and the Electoral Consequences of Western European Parties’ Policy Shifts, 1976-1998, American Journal of Political Science, 50(3), 513-529.

Alonso, S. (2012). Challenging the State: Devolution and the Challenge of Partisan Credibility. Oxford University Press. 
Alonso S., Cabeza, L. y Gómez, B. (2013). Manipulating Electoral Externalities in Multi-Level Systems: The Case of PSOE and PP in Spain, Paper presented at the ECPR General Conference 2013, Bordeaux 4-7 September.

Balcells i Ventura, L. (2007). ¿Es el voto nacionalista un voto de proximidad o un voto de compensación? Una nueva aproximación «espacial» al voto en dos dimensiones $R e$ vista Española de Ciencia Política, 16, 61-88.

Blanco Casais, M. (2013). Alternativa Galega de Esquerdas: un actor diferencial en las elecciones gallegas de 2013, RIPS. Revista de Investigaciones Políticas y Sociológicas, 12 (3), 143-161.

Carbajo Vázquez, J. (2016). El Partido Socialista Galego (PSG) y el discurso de los derechos del Franquismo a la Transición Democrática, Salamanca: Universidad de Salamanca Ediciones.

Casal Bértoa, F. y Rama, J. (2017). ¿Democracia en crisis? El futuro de los partidos políticos y de la democracia representativa. Paper presentado en el Congreso Internacional Calidad Democrática y Organización Territorial, Calatayud, 26 de septiembre de 2017.

CIS. Estudio Postelectoral de Galicia. Elecciones Autonómicas 2016 (estudio 3155). Enlace web: http://www.cis.es/cis/opencm/ES/1_encuestas/estudios/ver.jsp?estudio=14310\& cuestionario $=17171 \&$ muestra $=23860$

CIS. Estudio Postelectoral de Galicia. Elecciones Autonómicas 2012 (estudio 2963). Enlace web: http://www.cis.es/cis/opencm/ES/1_encuestas/estudios/ver.jsp?estudio=13304\& cuestionario $=15478 \&$ muestra $=21781$

Dalton, R. J., Flanagan, S.C. y Beck, P.A. (1984). Electoral Change in Advanced Industrial Democracies. Realignment or Dealignment? Princeton: Princeton University Press.

Elias, A. (2009). From Protest to Power: Mapping the Ideological Evolution of Plaid Cymru and the Bloque Nacionalista Galego, Regional and Federal Studies, 19 (4-5), 533-557.

Fernández Albertos, J. (2015). Los votantes de Podemos: del partido de los indignados al partido de los excluidos, Madrid: La Catarata.

Fraile, M., y Pérez-Nievas, S. (2000). Is the nationalist vote really nationalist? Dual voting in Catalonia 1980-1999. Madrid: Instituto Juan March de Estudios e Investigaciones, Working Paper 2000/147.

Gómez-Reino, M. (2006). The Bloque Nacionalista Galego: from political outcast to success, en L. de Winter, M. Gómez-Reino y P. Lynch (coords.), Autonomist parties in Europe: 
identity politics and the revival of the territorial cleavage (vol. I). Barcelona: Institut de Ciències Politiques i Socials.

Gómez-Reino, M. (2009). El nacionalismo minoritario, de la marginalidad al gobierno: la trayectoria del Bloque Nacionalista Galego (1982-2007), Papers: revista de sociología, 92, 119-142.

Hernández, E. y Kriesi, H. (2016). The Electoral Consequences of the Financial and Economic Crisis in Europe. European Journal of Political Research, 55 (2): 203-240. doi:10.1111/1475-6765.12122

Harmel, R y Robertson, J.H. (1985). Formation and Success of New Parties. International Political Science Review, 6, 501-23.

Hooghe, L., Marks, G., Schakel, A. H., Niedzwiecki, S., Osterkatz, Sa. C., y Shair-Rosenfield, S. (2016). Measuring regional authority. Oxford: Oxford University Press.

Hutters, S., Kriesi, H. y Vidal, G. (2018). Old versus new politics: The political spaces in Southern Europe in times of crises, Party Politics, 24(1), 10-22.

Kriesi, H., Grande, E., Dolezal, M., Bornschier, S. y Frey, T. (2006). Globalization and the Transformation of the National Political Space: Six European Countries Compared, European Journal of Political Research, 45, 921-56.

Kriesi, H., E. Grande, M. Dolezal, M. Helbling, S. Hutter y Wüst, B. (2012). Political Conflict in Western Europe. Cambridge: Cambridge University Press.

Lago, I. (2004). La coordinación electoral del nacionalismo gallego, Revista Internacional de Sociología, 39, 35-61.

Máiz, R. (1996). Nación de Breogán: Oportunidades políticas y estrategias enmarcadoras en el movimiento nacionalista gallego (1886-1996), Revista de Estudios Políticos, 92, 33-75.

Márquez, G. (2014). La formación de los gobiernos autonómicos en Galicia, en J. Ma Reniu (ed.), Los gobiernos de coalición de las Comunidades Autónomas españolas. Barcelona: Atelier.

Meguid, B. (2005). Competition Between Unequals: The Role of Mainstream Party Strategy in Niche Party Success, American Political Science Review, 99(3), 347-359.

Ocaña, F. y Oñate, P. (2000). Las elecciones autonómicas de 1999 y las Españas electorales, Revista Española de Investigaciones Sociológicas, 90, 183-228. 
Pallarés, F. y Lago, I. (2005). Las elecciones autonómicas de 2005 en Galicia, Informe Comunidades Autónomas 2005, Barcelona: Instituto de Derecho Público, 733-751.

Rivera, J.M., Lagares, M.N., Castro, A. y Diz, I. (1998a). Las elecciones autonómicas en Galicia, en Manuel Alcántara y Antonia Martínez (Eds.), Las elecciones autonómicas en España, 1980-1997. Madrid: Centro de Investigaciones Sociológicas.

Rivera, J.M., Lagares, M.N., Castro, A. y Diz, I. (1998b). Sistema electoral y elecciones autonómicas en Galicia, en Juan Montabes, (ed.), El sistema electoral a debate. Veinte años de rendimientos del sistema electoral español. Madrid: Centro de Investigaciones Sociológicas/Parlamento de Andalucía.

Rama Caamaño, J. y Fernández Esquer, C. (2017). Balance dos rendementos do sistema electoral galego: unha proposta de reforma. Revista de Investigaciones Políticas y Sociológicas, 16(1), 9-40.

Rokkan, S. y Urwin, D. (1983). Economy, Territory, Identity. Politics of West European Peripheries. Londres: Sage Publications.

Santana, A. y Rama, J. (2017). Manual de Análisis de Datos con Stata, Madrid: Técnos.

Scantamburlo, M., Alonso, S., y Gómez, B. (2017). Democratic regeneration in European peripheral regions: new politics for the territory?, West European Politics, DOI: 10.1080/01402382.2017.1403148

Vilas Nogueira, J. (1992). Las elecciones autonómicas de Galicia (1881-1990), Revista de Estudios Políticos, 75, 59-85.

Vilas Nogueira, J. y Fernández Baz, M.A. (2004). El BNG: definición y evolución de su estructura organizativa, Revista de Estudios Políticos, 123, 201-222.

\section{Fuentes}

El País, 29 de enero de 2012 «La UPG pondrá rostro al Bloque». Acceso online: https:// elpais.com/ccaa/2012/01/29/galicia/1327871751_793754.html

El Mundo del 29 de enero de 2012 «El Bloque Nacionalista Galego, un partido “dividido en dos"». Acceso online: http://www.elmundo.es/elmundo/2012/01/29/galicia/1327843445.html

La Voz de Galicia, 30 de enero de 2012 «La asamblea del Bloque deja el frente dividido en dos mitades». Acceso online: https://www.lavozdegalicia.es/noticia/galicia/2012/01/30/ asamblea-bloque-deja-frente-dividido-dos-mitades/0003_201201G30P2991.htm 
«Otra vuelta de tuerka». Pablo Iglesias con Xosé Manuel Beiras en la red social YouTube. Acceso online: https://www.youtube.com/watch?v=WxVrmB5IsVU

El Español, 9 de agosto de 2016 «Adiós a Beiras: el león blanco del nacionalismo gallego deja de rugir». Acceso online: https://www.elespanol.com/ espana/20160808/146236293_0.html

ABC, 17 de septiembre de 2012 «Huérfanos de un padre «traidor»». Acceso online: http:// www.abc.es/elecciones/gallegas/2012/abcp-huerfanos-padre-traidor-20120911.html

El Correo Gallego, 16 de diciembre de 2012 «Xoán Bascuas, elegido secretario xeral de CxG». Acceso online: http://www.elcorreogallego.es/galicia/ecg/xoan-bascuaselegido-secretario-xeral-cxg/idEdicion-2012-12-16/idNoticia-781815/

La Vanguardia, 14 de julio de 2012 «Beiras cree que el referente del nuevo proyecto nacionalista, que tiene 'las puertas abiertas', debe 'ser colectivo'». Acceso online: http:// www.lavanguardia.com/local/20120714/54325216702/beiras-cree-que-el-referentedel-nuevo-proyecto-nacionalista-que-tiene-las-puertas-abiertas.html

Europa Press, 11 de septiembre del 2012 «Anova e IU se presentarán como "Alternativa Galega de Esquerda”». Acceso online: http://www.europapress.es/galicia/noticia-anovaiu-presentaran-alternativa-galega-esquerda-20120911171855.html

El Confidencial, 24 de septiembre de 2017 «El soberanista gallego que susurra al oído de Pablo Iglesias la estrategia ante el 1-0». Acceso online: https://www.elconfidencial.com/ espana/2017-09-24/beiras-iglesias-podemos-estrategia-referendum-cataluna_1447736/

La Opinión A Coruña, 28 de mayo del 2014 «Beiras: "Sintonizo con Pablo Iglesias, es un pionero de la nueva cultura política”». Acceso online: http://www.laopinioncoruna.es/ galicia/2014/05/28/beiras-sintonizo/845679.html

El Mundo, 24 de enero del 2012 «Beiras: 'Francisco Rodríguez siempre está en la sombra, va a durar más que Franco’». Acceso online: http://www.elmundo.es/ elmundo/2012/01/24/galicia/1327438085.html

Faro de Vigo, 16 de junio del 2012 «El adiós de Francisco Rodríguez abre un relevo generacional en la UPG». Acceso online: http://www.farodevigo.es/galicia/2012/06/16/adiosfrancisco-rodriguez-abre-relevo-generacional-upg/657506.html

La Voz de Galicia, 26 de febrero del 2016 «Vence insiste en reclamar una refundación a fondo del BNG para frenar su declive». Acceso online: https://www.lavozdegalicia. es/noticia/galicia/2016/02/25/vence-insiste-reclamar-refundacion-fondo-bng-frenardeclive/00031456401260314179959.htm 


\section{ANEXO}

Tabla 1

\begin{tabular}{|l|c|c|c|c|c|c|c|c|c|c|}
\hline & \multicolumn{4}{|c|}{2012} & \multicolumn{5}{|c|}{2016} \\
\cline { 2 - 12 } & N & Media & D.T & Min. & Max. & N & Media & D.T & Min. & Max. \\
\hline Género & 2995 & 0,52 & 0,50 & 0 & 1 & 2865 & 0,53 & 0,50 & 0 & 1 \\
\hline Educación & 2994 & 0,95 & 1,16 & 0 & 3 & 2858 & 1,21 & 1,07 & 0 & 3 \\
\hline Tamaño Municipio & 2995 & 3,11 & 1,25 & 1 & 5 & 2865 & 3,12 & 1,25 & 1 & 5 \\
\hline Asistencia religiosa & 2416 & 0,21 & 0,41 & 0 & 1 & 2225 & 0,18 & 0,38 & 0 & 1 \\
\hline Desempleado & 2988 & 0,18 & 0,39 & 0 & 1 & 2853 & 0,12 & 0,33 & 0 & 1 \\
\hline Ideología & 2366 & 5,00 & 2,11 & 1 & 10 & 2368 & 4,93 & 2,08 & 1 & 10 \\
\hline Valoración economía Galicia & 2975 & 0,29 & 0,45 & 0 & 1 & 2843 & 0,56 & 0,49 & 0 & 1 \\
\hline Valoración economía personal & 2966 & 0,78 & 0,41 & 0 & 1 & 2836 & 0,82 & 0,38 & 0 & 1 \\
\hline Valoración política Galicia & 2809 & 0,42 & 0,49 & 0 & 1 & 2813 & 0,58 & 0,49 & 0 & 1 \\
\hline Valoración política España & 2787 & 0,30 & 0,46 & 0 & 1 & 2796 & 0,20 & 0,40 & 0 & 1 \\
\hline Escala de nacionalismo & 2647 & 4,30 & 2,35 & 1 & 10 & 2522 & 4,29 & 2,44 & 1 & 10 \\
\hline Sentimiento Nacional & 2962 & 2,15 & 0,49 & 1 & 3 & 2829 & 2,20 & 0,53 & 1 & 3 \\
\hline Preferencia Organización Territorial & 2707 & 1,85 & 0,64 & 1 & 3 & 2647 & 2,00 & 0,62 & 1 & 3 \\
\hline
\end{tabular}


¿Voto nacionalista? | José Rama Caamaño, Carlos Fernández Esquer, José Manuel Pantín Morado Correo

Tabla 2. Modelo de regresión logística para voto a AGE en 2012 y En Marea en 2016

\begin{tabular}{|c|c|c|}
\hline & $\begin{array}{c}\text { Modelo } 1 \\
\text { AGE }\end{array}$ & \begin{tabular}{|l} 
Modelo 2 \\
En Marea \\
\end{tabular} \\
\hline Mujer & $\begin{array}{c}-0,124 \\
(0,209) \\
\end{array}$ & $\begin{array}{c}-0,607^{* * *} \\
(0,218)\end{array}$ \\
\hline Secundaria & $\begin{array}{c}0,645^{* *} \\
(0,303)\end{array}$ & $\begin{array}{c}0,337 \\
(0,317)\end{array}$ \\
\hline Formación Profesional & $\begin{array}{l}0,708^{* *} \\
(0,277)\end{array}$ & $\begin{array}{l}0,696^{* *} \\
(0,349)\end{array}$ \\
\hline Universitarios & $\begin{array}{l}0,914^{* * *} \\
(0,286)\end{array}$ & $\begin{array}{l}0,597^{*} \\
(0,360)\end{array}$ \\
\hline 2.001 a 10.000 habitantes & \begin{tabular}{|c}
$-0,996^{*}$ \\
$(0,522)$ \\
\end{tabular} & $\begin{array}{c}0,326 \\
(0,587)\end{array}$ \\
\hline 10.001 a 50.000 habitantes & $\begin{array}{c}0,475 \\
(0,474)\end{array}$ & $\begin{array}{l}1,437^{* *} \\
(0,563)\end{array}$ \\
\hline 50.001 a 100.000 habitantes & $\begin{array}{c}-0,271 \\
(0,543)\end{array}$ & $\begin{array}{l}1,185^{*} \\
(0,612)\end{array}$ \\
\hline 100.001 a 400.000 habitantes & $\begin{array}{c}0,621 \\
(0,489) \\
\end{array}$ & $\begin{array}{c}1,313^{* *} \\
(0,580)\end{array}$ \\
\hline Asistencia religiosa & \begin{tabular}{|c}
$-0,877^{* *}$ \\
$(0,431)$ \\
\end{tabular} & $\begin{array}{l}-0,504 \\
(0,547) \\
\end{array}$ \\
\hline Desempleado & $\begin{array}{c}-0,502 * \\
(0,275)\end{array}$ & $\begin{array}{c}0,078 \\
(0,304)\end{array}$ \\
\hline Ideología & $\begin{array}{l}-0,434^{* * *} \\
(0,074)\end{array}$ & $\begin{array}{c}-0,686^{* * *} \\
(0,078)\end{array}$ \\
\hline Valoración situación económica Galicia & $\begin{array}{c}-0,956^{* * *} \\
(0,363)\end{array}$ & $\begin{array}{l}-0,391 \\
(0,252)\end{array}$ \\
\hline Valoración situación económica personal & \begin{tabular}{|l}
$-0,355$ \\
$(0,291)$ \\
\end{tabular} & $\begin{array}{c}-0,364 \\
(0,291)\end{array}$ \\
\hline Valoración situación política Galicia & \begin{tabular}{|c|}
0,217 \\
$(0,349)$ \\
\end{tabular} & $\begin{array}{l}-0,302 \\
(0,251) \\
\end{array}$ \\
\hline Valoración situación política España & $\begin{array}{c}-0,755^{*} \\
(0,437) \\
\end{array}$ & $\begin{array}{c}-0,722^{* *} \\
(0,326) \\
\end{array}$ \\
\hline Escala de Nacionalismo & $\begin{array}{c}0,054 \\
(0,051) \\
\end{array}$ & $\begin{array}{c}0,008 \\
(0,047) \\
\end{array}$ \\
\hline Sentimiento igual gallego que español & $\begin{array}{c}1,329 \\
(1,034)\end{array}$ & $\begin{array}{c}0,490 \\
(0,661)\end{array}$ \\
\hline Sentimiento más gallego que español & $\begin{array}{r}1,910^{*} \\
(1,064)\end{array}$ & $\begin{array}{c}0,844 \\
(0,691)\end{array}$ \\
\hline Un estado como el actual & $\begin{array}{l}1,028^{* * *} \\
(0,338)\end{array}$ & $\begin{array}{l}-0,057 \\
(0,309)\end{array}$ \\
\hline Un estado más descentralizado & $\begin{array}{l}1,319 * * * \\
(0,403)\end{array}$ & $\begin{array}{c}0,369 \\
(0,352)\end{array}$ \\
\hline Constante & $\begin{array}{c}-2,881^{* *} \\
(1,200) \\
\end{array}$ & $\begin{array}{c}-0,388 \\
(0,962) \\
\end{array}$ \\
\hline $\begin{array}{l}\text { N. }{ }^{\circ} \text { observaciones } \\
\text { Pseudo } \mathrm{R}^{2}\end{array}$ & $\begin{array}{l}1,608 \\
0,259\end{array}$ & $\begin{array}{l}1,533 \\
0,286\end{array}$ \\
\hline
\end{tabular}

Errores estándar entre paréntesis.

*** $\mathrm{p}<0.01,{ }^{* *} \mathrm{p}<0.05,{ }^{*} \mathrm{p}<0.1$ 
Tabla 3. Modelo de regresión logística para voto al BNG en 2012 y 2016

\begin{tabular}{|c|c|c|}
\hline & \begin{tabular}{|l|} 
Modelo 1 \\
BNG 2012 \\
\end{tabular} & $\begin{array}{l}\text { Modelo } 2 \\
\text { BNG } 2016 \\
\end{array}$ \\
\hline Mujer & $\begin{array}{c}0,560 * * \\
(0,244)\end{array}$ & $\begin{array}{c}0,073 \\
(0,295)\end{array}$ \\
\hline Secundaria & \begin{tabular}{|l|}
$-0,065$ \\
$(0,367)$ \\
\end{tabular} & $\begin{array}{c}0,094 \\
(0,400) \\
\end{array}$ \\
\hline Formación Profesional & $\begin{array}{c}0,051 \\
(0,306)\end{array}$ & $\begin{array}{c}0,194 \\
(0,468)\end{array}$ \\
\hline Universitarios & \begin{tabular}{|l|}
$-0,250$ \\
$(0,352)$ \\
\end{tabular} & $\begin{array}{c}0,256 \\
(0,464)\end{array}$ \\
\hline 2.001 a 10.000 habitantes & $\begin{array}{c}0,149 \\
(0,485)\end{array}$ & $\begin{array}{l}-1,085^{* *} \\
(0,476)\end{array}$ \\
\hline 10.001 a 50.000 habitantes & $\begin{array}{c}0,106 \\
(0,496)\end{array}$ & $\begin{array}{l}-1,369 * * * \\
(0,498)\end{array}$ \\
\hline 50.001 a 100.000 habitantes & $\begin{array}{c}-1,371^{* *} \\
(0,663) \\
\end{array}$ & $\begin{array}{l}-1,417^{* *} \\
(0,616) \\
\end{array}$ \\
\hline 100.001 a 400.000 habitantes & $\begin{array}{c}0,025 \\
(0,521)\end{array}$ & $\begin{array}{l}-1,712^{* * *} \\
(0,554)\end{array}$ \\
\hline Asistencia religiosa & \begin{tabular}{|l|}
$-0,326$ \\
$(0,393)$ \\
\end{tabular} & $\begin{array}{l}-0,275 \\
(0,644)\end{array}$ \\
\hline Desempleado & $\begin{array}{c}-0,019 \\
(0,300)\end{array}$ & $\begin{array}{c}0,673 \\
(0,424)\end{array}$ \\
\hline Ideología & $\begin{array}{l}-0,496 * * * \\
(0,084)\end{array}$ & $\begin{array}{l}-0,547^{* * *} \\
(0,108)\end{array}$ \\
\hline Valoración situación económica Galicia & $\begin{array}{c}0,346 \\
(0,346)\end{array}$ & $\begin{array}{c}-0,369 \\
(0,333)\end{array}$ \\
\hline Valoración situación económica personal & $\begin{array}{c}-0,382 \\
(0,297) \\
\end{array}$ & $\begin{array}{c}0,855^{*} \\
(0,466) \\
\end{array}$ \\
\hline Valoración situación política Galicia & $\begin{array}{l}-0,959 * * \\
(0,472) \\
\end{array}$ & $\begin{array}{c}0,208 \\
(0,343) \\
\end{array}$ \\
\hline Valoración situación política España & $\begin{array}{c}-0,097 \\
(0,549) \\
\end{array}$ & $\begin{array}{c}-0,019 \\
(0,410)\end{array}$ \\
\hline Escala de Nacionalismo & $\begin{array}{l}0,193^{* * *} \\
(0,059)\end{array}$ & $\begin{array}{l}0,248^{* * *} \\
(0,070)\end{array}$ \\
\hline Sentimiento igual gallego que español & $\begin{array}{l}-0,554 \\
(0,567)\end{array}$ & $\begin{array}{l}-0,226 \\
(0,318)\end{array}$ \\
\hline Sentimiento más gallego que español & $\begin{array}{l}-0,236 \\
(0,612)\end{array}$ & - \\
\hline Un estado como el actual & $\begin{array}{c}0,437 \\
(0,365)\end{array}$ & $\begin{array}{c}0,140 \\
(0,569)\end{array}$ \\
\hline Un estado más descentralizado & $\begin{array}{l}1,148^{* * *} \\
(0,419)\end{array}$ & $\begin{array}{l}1,479 * * \\
(0,579)\end{array}$ \\
\hline Constante & \begin{tabular}{|c|}
$-1,290$ \\
$(0,847)$ \\
\end{tabular} & $\begin{array}{c}-2,002^{* *} \\
(1,013) \\
\end{array}$ \\
\hline $\begin{array}{l}\mathrm{N}^{0} \text { observaciones } \\
\text { Pseudo } \mathrm{R}^{2}\end{array}$ & $\begin{array}{l}1,608 \\
0,232\end{array}$ & $\begin{array}{l}1,432 \\
0,278\end{array}$ \\
\hline
\end{tabular}

Errores estándar entre paréntesis.

$* * * \mathrm{p}<0.01, * * \mathrm{p}<0.05, * \mathrm{p}<0.1$. 